\title{
Caracterización y tecnología de materiales cerámicos romanos de los ss. I a III d.c procedentes del Hospital de las Cinco Llagas de Sevilla
}

\author{
A.J. POLVORINOS DEL RÍO(*), V. FLORES ${ }^{(*)}, M^{(A .}$. TABALES ${ }^{(*)}$, M.J. HERNÁNDEZ ${ }^{(*)}$ \\ (*) Dpto. de Cristalografía Mineralogía y Q. Agrícola. Facultad de Química. Universidad de Sevilla. \\ ${ }^{* *)}$ Dpto. de Construcciones Arquitectónicas II. E.U.Arquitectura Técnica. Universidad de Sevilla.
}

\begin{abstract}
El objeto de este trabajo es la caracterización arqueométrica de las cerámicas encontradas a raíz de las excavaciones arqueológicas realizadas en el Hospital de las Cinco Llagas (Sevilla). Durante el periodo de ocupación romana de la zona se han distinguido tres tipos de cerámicas, procedentes de ánforas vinarias, oleicas y de salazón adscritas a los ss. I y III d.C. Las 14 cerámicas seleccionadas para su estudio representan adecuadamente la diversidad espacio-temporal y tipológica de los materiales excavados. De las 14 muestras estudiadas, además de tres muestras de importación, probablemente lusitana y campaniense (Italia), se han determinado dos grupos de ánforas bien representadas, uno de producción local que corresponde al alfar excavado, y otro regional, de localización aún no concretada pero probablemente próximo a la costa. La mineralogía de las arcillas empleadas en ambos centros productores de ánforas es muy similar y de naturaleza calcárea; la cocción de todas las cerámicas se ha realizado en condiciones oxidantes, si bien las fases de transformación térmica indican una reducción en la temperatura de cocción entre las cerámicas adscritas al s.I d.C y al s.III d.C; del análisis de la estructura de correlación de las variables de composición química, así como del análisis granulométrico del desgrasante, se sugiere la probable utilización de procedimientos de decantación y / o legivación para elaborar las pastas cerámicas en el alfar Q-II y de mezcla de arcillas ó adición de desgrasante en el caso del alfar excavado en el Hospital de las Cinco Llagas de Sevilla (España).
\end{abstract}

Palabras clave: arqueometría, cerámica, difracción de rayos $X$, fluorescencia de rayos $X$, petrografía cuantitativa, morfometría, granulometría, cuenca del Guadalquivir, Sevilla, siglos I a III d.C..

Characterization and technology of Roman ceramic materials dated between the $1^{\text {st }}$ and $3^{\text {rd }}$ centuries AD from the Hospital de las Cinco Llagas of Seville

The aim of this work is the archaeometric characterization of the ceramics found in the archaeological excavations carried out in the Hospital de las Cinco Llagas (Seville, Spain). During the Roman occupation period of the area, three main types of amphorae -for wine, oil and fish sauces - have been distinguished, dated from the first to the third centuries AD. The selection of samples made for this study is intended as a wide representation of the dispersion in time, space and typology of the materials excavated. Three of the fourteen samples studied here were probably imported from Lusitania and the region of Campania in southern Italy. Two other amphorae groups have been distinguished, one of them produced locally and the other from a location probably close to the coast (although this has not been established with security). The mineralogy of the clays used at both sites has calcite and a very similar structure; oxidant atmospheres have been applied in all cases, and the firing temperatures of the ceramics dated from the first century AD are higher than those of the third century AD amphorae. Correlation structure analysis of the chemical composition variables and temper granulometry analysis suggests that legivation and/or decantation of clays have been used to prepare the ceramic paste of the pottery Q-II, while clay mixing or temper added to clay seems to have been used in the Q-I pottery located in the Hospital de las Cinco Llagas, of Seville (Spain).

Key words: archaeometry, ceramics, X-ray diffracción, X-ray fluorescence, quantitative petrography, morphometry, granulometry, Guadalquivir basin, Seville, 1 st and $3 r d$ centuries $A D$.

\section{INTRODUCCIÓN}

La caracterización del conjunto de piezas estudiadas en el presente trabajo se ha abordado tras la localización de hornos cerámicos en una zona cercana a los límites urbanos de la ciudad de Híspalis (Sevilla), en el lugar ocupado por el antiguo Hospital de las Cinco Llagas, hoy sede del Parlamento de Andalucía. Dicha ubicación, así como la excepcionalidad de un hallazgo semejante en la ciudad de Sevilla, determinó la necesidad de caracterizar las pastas de las producciones de dicha alfarería. La excavación del yacimiento se ha realizado en tres fases entre los años 1998 y 2001.

El estudio arqueológico del alfar, determinó tres episodios en la construcción de los hornos, iniciándose el proceso en las últimas décadas del s. I d.C. y finalizando en algún momento indeterminado durante el s. III d.C., época en la que deja de observarse actividad humana en el lugar. El estudio arqueológico se ha centrado en dos zonas, una de ellas con abundante presencia de ánforas de probable origen local adscritas al s. I d.C., que incluye las ánforas conocidas de los tipos Dressel 20, Haltern 70, Dressel 28, Beltrán IIA y Beltrán IIB [3, 4], y otra constituida por rellenos cerámicos de los ss. II y III d.C. entre los que se encuentran cerámicas de imitación de los tipos de terra sigillata Clara y ánforas de origen gaditano tipo Keay XVI [5,6]. 
En ambas zonas se excavaron un total de 6 hornos, 5 en la zona I adscrita al s. I d.C. y uno en la zona II de cronología posterior, todos ellos del tipo Fletcher-Valls ${ }^{\circ} 1$. Durante la excavación se recogieron distintos materiales, tales como cerámica de uso común, terra sigillata, materiales constructivos diversos como laterculi, ímbrices y ladrillos, así como abundantes restos de ánforas que representan más del $60 \%$ del total.

Entre los grupos anfóricos encontrados, el dedicado al transporte de aceite es el de mayor índice de presencia, y corresponden a contenedores del tipo Dressel 20, el envase de aceite bético por excelencia. Este tipo de ánforas se produjo en los talleres cerámicos de los valles del Guadalquivir y Genil entre los siglos I y III d.C, siendo sustituidas a partir de esta fecha por las Dressel 23 que se caracterizan por una mayor variabilidad formal y un tamaño menor.

En el alfar del Parlamento de Andalucía se documentan otras ánforas dedicadas al transporte de vino y otros derivados de la uva. La tipología Dressel 28, que parece haberse utilizado también para transportar vino bético desde la época de Augusto a la mitad al menos del siglo II d. C., es otra de estas producciones béticas, cuyos centros de producción en el Guadalquivir se encuentran peor definidos.

Un conjunto reducido de piezas de morfologías Dressel 7-11 y Beltrán IIA probablemente se utilizarían como contenedores de salsas, si bien es posible su uso alternativo como recipientes vinarios. Las cerámicas asociadas al transporte de producciones salsarias de tipologías Keay XVI, Dressel 14 y Beltrán 72 se datan en fechas de inactividad del alfar por lo que su contexto de consumo no está bien determinado.

El análisis tipológico y de la diversidad espacio-temporal de las ánforas recogidas durante la excavación se aborda a partir del estudio de los 14 fragmentos seleccionados, si bien no se agota la necesidad de estudios más extensos de cada una de las tipologías aquí analizadas.

En este estudio arqueométrico se tratan de establecer diversos aspectos tecnológicos de la producción anfórica, el probable origen local ó foráneo de cada una de las piezas estudiadas, así como estimar la capacidad productiva local de cada tipología.

\section{MATERIALES Y METODOLOGÍA}

Las 14 muestras de cerámicas estudiadas se han seleccionado de forma que son representativas de los distintos periodos de ocupación, de los distintos contextos excavados, así como de las diversas tipologías encontradas (Tabla 1). Cada resto cerámico ha sido descrito por parámetros macroscópicos tales como tipología, objeto, cronología, parámetros de medida de color $(\mathrm{L}, \mathrm{b}, \mathrm{a})$, espesor de la pared y presencia de engobes.

El análisis del color de cada fragmento se ha realizado midiendo su reflectancia difusa con un colorímetro portátil Dr.Lange Color-pen; se han medido los tres parámetros básicos (tono, saturación y brillo), utilizando como referencia la escala CIE-Lab; dichos valores se han medido sobre secciones trasversales a la pared de cada fragmento y promediando en un mínimo de 10 puntos distintos.

La caracterización mineralógica por difracción de rayos- $X$ [7], se ha realizado con un difractómetro Phillips PW1130/90 dotado con rendija automática, radiación $\mathrm{Cu}-\mathrm{K} \alpha$, filtro de $\mathrm{Ni}$, y unas condiciones de trabajo de $40 \mathrm{kV}$ y $20 \mathrm{~mA}$. Los diagramas se realizaron en muestras pulverizadas en un mortero de ágata
TABLA 1 MUESTRAS ESTUDIADAS Y ADCRIPCIÓN ESPACIO-TEMPORAL

\begin{tabular}{|l|l|l|l|l|l|l|l|l|}
\hline Mues. & Tipología & Objeto & Cronol. & L & b & a & Esp. & Engob. \\
\hline Par1 & Beltrán IIB & Borde & S. I d.C. & 65.1 & 10.9 & 21.7 & 2.2 & No \\
\hline Par2 & Dressel 20 & Galbo & S. I d.C. & 64.6 & 9.9 & 23.6 & 2.1 & Si \\
\hline Par3 & Beltrán IIA & Galbo & S. I d.C. & 57.9 & 8.2 & 19.6 & 1.35 & No \\
\hline Par4 & Fallo alfar & & & 47.1 & 0.8 & 5.2 & & \\
\hline Par5 & Dressel 30 & Borde & S. III d.C. & 53.6 & 0.7 & 5.7 & 0.65 & No \\
\hline Par6 & Dressel 14 & Borde & S. III d.C. & 76.6 & 2.2 & 19.7 & 1.15 & No \\
\hline Par7 & Keay XVI & Borde & S. III d.C. & 69.3 & 6.1 & 19.1 & 0.85 & No \\
\hline Par8 & Keay XVI & Regatón & S. III d.C. & 68.7 & 4.9 & 17.5 & 0.75 & No \\
\hline Par9 & Dress.7-11 & Regatón & S. I d.C. & 72.7 & 0.3 & 10.1 & 1.15 & No \\
\hline Par10 & Majuelo 1 & Borde & S. III d.C. & 63.8 & 11.0 & 24.8 & 1.15 & No \\
\hline Par11 & Dressel 20 & Borde & S. III d.C. & 57.3 & 7.9 & 19.3 & 1.15 & No \\
\hline Par12 & Keay XVI & Borde & S. III d.C. & 71.0 & 5.2 & 18.8 & 1.25 & No \\
\hline Par13 & Dressel 2-4 & Galbo & S. III d.C. & 55.4 & 13.8 & 23.7 & 0.6 & No \\
\hline Par14 & Dressel 28 & Borde & S. I d.C. & 72.1 & 1.6 & 13.5 & 1.1 & No \\
\hline
\end{tabular}

y tamizadas a $50 \mu \mathrm{m}$ en el rango de $5^{\circ}$ a $50^{\circ}$ con un paso angular de $0.02^{\circ}$ y 2 s de tiempo de conteo.

El análisis químico se realizó por fluorescencia de rayos $X$ en un espectrómetro secuencial Philips PW1480 que incorpora cambiador automático de muestras, 8 cristales analizadores y 3 colimadores, utilizando un tubo dual Sc-Mo. Las muestras, previamente molidas a tamaños inferiores a $60 \mu \mathrm{m}$ y secadas a $105^{\circ} \mathrm{C}$ durante $24 \mathrm{~h}$ fueron procesadas en una perladora de inducción por radiofrecuencia Philips Perlx'2 siguiendo un protocolo convencional, determinándose su contenido en óxidos mayoritarios $\left(\mathrm{SiO}_{2}, \mathrm{Al}_{2} \mathrm{O}_{3}, \mathrm{Fe}_{2} \mathrm{O}_{3}, \mathrm{MnO}, \mathrm{MgO}, \mathrm{CaO}, \mathrm{Na}_{2} \mathrm{O}\right.$, $\mathrm{K}_{2} \mathrm{O}, \mathrm{TiO}_{2}, \mathrm{P}_{2} \mathrm{O}_{5}$ ), y elementos trazas (As, $\mathrm{Ba}, \mathrm{Co}, \mathrm{Cu}, \mathrm{Nb}, \mathrm{Ni}$, $\mathrm{Rb}, \mathrm{Sr}, \mathrm{V}, \mathrm{Y}, \mathrm{Zn}, \mathrm{Zr}$ ); así mismo se determinó la pérdida por calcinación.

La metodología empleada para la determinación de parámetros texturales y granulométricos del desgrasante de cada cerámica se basa en el análisis digital de láminas delgadas convencionales. Básicamente el proceso consta de tres fases secuenciales: captación de imágenes, procesado digital de éstas, y medida de los distintos parámetros de forma y tamaño en cada grano mineral identificado en la fase anterior. Para captar las imágenes se ha utilizado un digitalizador de diapositivas y un adaptador especialmente diseñado a tal fin [8], obviando las dificultades de la utilización de equipos conectados a microscopios. De cada lámina se han captado una imagen con luz polarizada paralela y cuatro imágenes con nícoles cruzados en distintas posiciones angulares respecto de la lámina que permanece fija por lo que todas las imágenes de cada lámina cubren la misma superficie. Se ha utilizando una resolución de 2000 puntos por pulgada cubriendo una superficie amplia y que incluyese la mayor cantidad posible de granos minerales. Del análisis de las imágenes de brillo, se han discriminado los minerales no plásticos de cada lámina utilizando procedimientos de tratamiento digital de imágenes $[9,10]$. Finalmente de las imágenes binarias del desgrasante se han cuantificado diversos parámetros de forma y tamaño (superficie, perímetro, longitud máxima y mínima, elongación, redondez, diámetro Feret y compacidad) de cada grano mineral [11,12], así como su granulometría.

La integración e interpretación de los resultados de composición química y morfométrica se ha realizado a partir de diversos procedimientos de análisis estadístico, que incluyen tanto los descriptivos como de análisis multivariante [13]. 


\section{RESULTADOS Y DISCUSIÓN}

\subsection{Análisis mineralógico y condiciones de cocción}

Las 14 cerámicas seleccionadas en este conjunto caracterizan la elevada diversidad de todas las recogidas durante la excavación (Tabla 1). El análisis de los diagramas de difracción de rayos $X$ se expone en la Tabla 2. Cabe destacar que, excepto las muestras Par5 y Par13, todas presentan como desgrasantes principales cuarzo, feldespatos y plagioclasas, así como cantidades variables de calcita y sus fases de transformación térmica gehlenita, piroxeno, y plagioclasas reactivas. Estas dos piezas diferentes, junto a la Par14, presentan una mineralogía peculiar y se han identificado como de origen foráneo. La cerámica Par5 corresponde a un ánfora oleica de tipología Dressel 23 adscrita al s.III d.C. de probable importación lusitana. El fragmento Par13 que corresponde a un ánfora vinaria de tipología Dressel 2-4, posiblemente procedente de La Campania (Italia).

Las condiciones de cocción establecidas a partir del análisis mineralógico de las cerámicas pertenecientes al s.I d.C. indican un amplio rango térmico, entre $700^{\circ}$ y $950^{\circ} \mathrm{C}$, así como atmósferas oxidantes. Significativamente distinta es la cerámica Par4, correspondiente a un fallo de alfar, que ha alcanzado una temperatura tan elevada que se ha producido su vitrificación, encontrándose piroxeno y plagioclasa como fases de reacción entre la calcita descompuesta y los filosilicatos de la arcilla. Esta cerámica probablemente llegó a alcanzar temperaturas superiores a $1000^{\circ} \mathrm{C}$; la observación petrográfica de su lámina delgada indica claramente la zonación concéntrica de las coronas de reacción, así como el intenso desarrollo de poros esféricos. El resto de estas cerámicas, presentan temperaturas de cocción variables, desde las más bajas temperaturas, del orden de $700^{\circ} \mathrm{C}$, de la cerámica Par3, en la que no se detecta la descomposición de la calcita ni de los filosilicatos, hasta las más altas, en torno a $950^{\circ} \mathrm{C}-1000^{\circ} \mathrm{C}$, de las cerámicas Par2 y Par9 en las que se llega a formar piroxeno y plagioclasa reactiva. Temperaturas intermedias de cocción ligeramente superiores a los $750^{\circ} \mathrm{C}$ corresponden al ánfora Par1, y del orden de $850^{\circ} \mathrm{C}$ el fragmento Par14. En cualquier caso dichos rangos están en consonancia con las observaciones petrográficas que se han realizado de las coronas de reacción desarrolladas en cada pasta cerámica.

Todas las cerámicas del s. III d.C. se caracterizan por la abundancia de cuarzo y calcita, excepto la muestra Par6, en que se promueve la total descomposición de la calcita y la formación de piroxeno, mientras que para todas las demás se puede estimar que sólo se ha alcanzado la temperatura de formación incipiente de gehlenita que se situaría en torno a $800-850^{\circ} \mathrm{C}$.

El análisis de la relación entre las temperaturas de cocción y el color de las pastas (Tabla 1) indica que las cerámicas que se han cocido a temperaturas más altas y probablemente durante más tiempo, es decir en las que la descomposición de calcita es total, presentan los colores más claros; por el contrario, aquellas pastas con abundante calcita, tienen los componentes rojo y amarillo mayores, debido a que la cocción se realizó a menores temperaturas $[14,15]$. Estos resultados son consecuentes con la incorporación de Fe en la estructura de los silicatos de transformación térmica desarrollados a alta temperaturas, mientras que en cocciones a más bajas temperaturas prevalecen las condiciones oxidantes dando lugar a la formación de óxidos de Fe dispersos en la pasta cerámica, lo que confiere a la cerámica colores más rojizos $[16,17]$.
TABLA 2 RESUlTADOS DEL ANÁLISIS POR DRX DE MUESTRAS ESTUDIADAS

\begin{tabular}{|l|l|l|l|l|l|l|l|l|l|}
\cline { 2 - 9 } \multicolumn{1}{l|}{} & Cuarzo & Calcita & Gehl. & Pirox. & Plagio. & Hem. & Arag. & Filos. & Anf. \\
\hline Par1 & M.A. & AB. & IND. & MED. & - & IND. & IND & - & - \\
\hline Par2 & M.A. & - & IND. & MED. & AB. & IND. & - & - & - \\
\hline Par3 & M.A. & AB. & - & - & MED. & - & IND & & - \\
\hline Par4 & M.A. & AB & - & MED. & MED. & - & - & - & - \\
\hline Par5 & M.A. & - & - & - & MED & - & - & - & - \\
\hline Par6 & M.A. & - & AB. & MED. & IND. & IND. & - & - & - \\
\hline Par7 & M.A. & AB. & MED. & IND. & MED & - & - & - & - \\
\hline Par8 & M.A. & AB. & MED. & IND. & IND. & - & - & - & - \\
\hline Par9 & M.A. & - & MED. & MED. & MED. & - & - & - & - \\
\hline Par10 & M.A. & AB. & IND. & - & IND. & - & - & - & - \\
\hline Par11 & M.A. & AB. & IND. & - & IND. & - & - & - & - \\
\hline Par12 & M.A. & AB. & MED. & - & IND. & - & - & - & - \\
\hline Par13 & AB. & - & - & - & - & - & - & - & AB. \\
\hline Par14 & AB. & IND. & IND. & AB. & MED. & - & - & - & - \\
\hline
\end{tabular}

Nota: Gehl: Gehlenita, Pirox. Piroxeno, Plag.: Plagioclasa, Hem: Hematite, Arag.: aragonito, Filos.: Filosilicatos, Anf: Anfíbol.

M.A. :Muy abundante; AB: Abundante; MED.:Medio; IND.:Indicios; -: No detectado

\subsection{Análisis químico}

Tras el análisis descriptivo inicial de las composición química determinada por fluorescencia de rayos- $X$ (Tablas 3 y 4), se ha realizado un análisis de conglomerados de todas las cerámicas utilizando los óxidos mayoritarios (Tabla 3) y elementos minoritarios (Tabla 4); el procedimiento de aglomeración empleado es el de unión simple de observaciones y la medida de separación entre observaciones empleada la euclídea; en dicho análisis se identifican las cerámicas Par5, Par13 y Par14 que se separan claramente del resto; estas mismas cerámicas ya se han diferenciado durante el análisis mineralógico, confirmándose el origen foráneo de estas ánforas. Del resto de las cerámicas se ha realizado un nuevo análisis de conglomerados que permite identificar dos grupos de cerámicas que en adelante denominaremos Q-I y Q-II; el grupo Q-I que integra las cerámicas Par2, Par3, Par9 y Par11, adscritas al s.I d.C. excepto la cerámica Par11 que pertenece a cronologías posteriores; en el grupo Q-II se incluyen las cerámicas Par1, Par6, Par7, Par8, Par10 y Par12, siendo todas ellas producidas en el s. III d.C. excepto la muestra Par1 que está datada como más reciente; este resultado sugiere que las materias primas utilizadas en la elaboración de ambos conjuntos de ánforas es distinto.

TABLA 3 ANÁLISIS QUÍMICO DE ÓXIDOS MAYORITARIOS Y PÉRDIDA DE CALCINACIÓN (\%).

\begin{tabular}{|l|c|c|c|c|c|c|c|c|c|c|c|}
\cline { 2 - 12 } \multicolumn{1}{c|}{} & $\mathrm{SiO}_{2}$ & $\mathrm{Al}_{2} \mathrm{O}_{3}$ & $\mathrm{Fe}_{2} \mathrm{O}_{3}$ & $\mathrm{MnO}$ & $\mathrm{MgO}$ & $\mathrm{CaO}$ & $\mathrm{Na}_{2} \mathrm{O}$ & $\mathrm{K}_{2} \mathrm{O}$ & $\mathrm{TiO}_{2}$ & $\mathrm{P}_{2} \mathrm{O}_{5}$ & P.C. \\
\hline PAR1 & 55.44 & 11.48 & 4.35 & 0.05 & 2.73 & 21.07 & 0.70 & 2.45 & 0.66 & 0.23 & 12.73 \\
\hline PAR2 & 58.32 & 14.02 & 5.68 & 0.03 & 2.15 & 15.36 & 0.48 & 1.65 & 0.71 & 0.17 & 4.83 \\
\hline PAR3 & 59.04 & 15.48 & 6.12 & 0.05 & 2.09 & 11.26 & 0.83 & 2.66 & 0.75 & 0.28 & 9.98 \\
\hline PAR4 & 57.86 & 11.23 & 4.36 & 0.07 & 2.49 & 16.00 & 1.24 & 2.88 & 0.74 & 0.35 & 7.28 \\
\hline PAR5 & 68.29 & 17.59 & 4.90 & 0.02 & 1.09 & 0.50 & 0.90 & 3.51 & 0.84 & 0.06 & 0.64 \\
\hline PAR6 & 55.26 & 11.67 & 4.35 & 0.06 & 2.97 & 21.94 & 1.11 & 1.77 & 0.69 & 0.14 & 9.89 \\
\hline PAR7 & 55.44 & 11.44 & 4.47 & 0.06 & 2.76 & 18.82 & 0.68 & 2.66 & 0.67 & 0.20 & 11.48 \\
\hline PAR8 & 56.32 & 10.21 & 3.87 & 0.07 & 3.07 & 21.26 & 0.96 & 2.18 & 0.66 & 0.22 & 14.42 \\
\hline PAR9 & 57.66 & 15.09 & 5.93 & 0.08 & 2.89 & 15.07 & 1.53 & 1.88 & 0.73 & 0.22 & 1.76 \\
\hline PAR10 & 54.20 & 11.96 & 4.51 & 0.06 & 2.69 & 20.73 & 0.63 & 2.53 & 0.70 & 0.20 & 13.54 \\
\hline PAR11 & 59.50 & 14.62 & 5.76 & 0.04 & 1.86 & 12.47 & 0.47 & 2.36 & 0.77 & 0.23 & 7.14 \\
\hline PAR12 & 53.25 & 11.92 & 4.63 & 0.08 & 3.02 & 23.11 & 0.57 & 2.54 & 0.72 & 0.29 & 12.61 \\
\hline PAR13 & 57.01 & 16.46 & 8.28 & 0.15 & 3.20 & 10.14 & 0.89 & 2.56 & 1.00 & 0.17 & 4.16 \\
\hline PAR14 & 51.64 & 16.69 & 6.55 & 0.09 & 3.56 & 16.18 & 1.18 & 2.72 & 0.72 & 0.25 & 4.01 \\
\hline
\end{tabular}


TABLA 4. ANÁLISIS QUÍMICO DE ELEMENTOS TRAZA (ppm).

\begin{tabular}{|l|c|c|c|c|c|c|c|c|c|c|c|c|c|}
\cline { 2 - 15 } \multicolumn{1}{c|}{} & AS & BA & CO & CR & CU & NB & NI & RB & SR & V & Y & ZN & ZR \\
\hline PAR1 & 8 & 875 & 16 & 69 & 31 & 69 & 38 & 136 & 441 & 95 & 0 & 85 & 225 \\
\hline PAR2 & 11 & 759 & 18 & 112 & 32 & 62 & 46 & 107 & 603 & 109 & 4 & 69 & 200 \\
\hline PAR3 & 17 & 1273 & 24 & 129 & 39 & 29 & 49 & 175 & 386 & 161 & 0 & 102 & 139 \\
\hline PAR4 & 10 & 828 & 11 & 73 & 36 & 58 & 41 & 159 & 332 & 98 & 0 & 67 & 255 \\
\hline PAR5 & 8 & 814 & 0 & 79 & 20 & 91 & 26 & 148 & 64 & 87 & 11 & 79 & 272 \\
\hline PAR6 & 7 & 784 & 19 & 69 & 20 & 48 & 34 & 137 & 420 & 90 & 0 & 77 & 252 \\
\hline PAR7 & 13 & 921 & 17 & 71 & 33 & 52 & 36 & 144 & 369 & 84 & 0 & 75 & 232 \\
\hline PAR8 & 8 & 974 & 26 & 57 & 29 & 46 & 36 & 112 & 426 & 64 & 7 & 71 & 274 \\
\hline PAR9 & 4 & 851 & 26 & 114 & 31 & 40 & 47 & 105 & 408 & 129 & 5 & 86 & 158 \\
\hline PAR10 & 11 & 892 & 19 & 74 & 37 & 94 & 40 & 162 & 370 & 96 & 0 & 71 & 238 \\
\hline PAR11 & 15 & 800 & 12 & 143 & 26 & 56 & 41 & 148 & 326 & 146 & 0 & 98 & 187 \\
\hline PAR12 & 15 & 860 & 18 & 76 & 27 & 56 & 35 & 145 & 410 & 73 & 0 & 82 & 254 \\
\hline PAR13 & 25 & 814 & 31 & 168 & 27 & 73 & 60 & 175 & 273 & 207 & 7 & 119 & 335 \\
\hline PAR14 & 21 & 849 & 8 & 115 & 47 & 33 & 50 & 244 & 346 & 138 & 0 & 83 & 97 \\
\hline
\end{tabular}

Con el objeto de analizar la estructura de la matriz de correlación entre los óxidos mayoritarios (Tabla 3) se ha realizado su análisis factorial. Eliminando las cerámicas Par5, Par13 y Par14, los dos factores extraídos acumulan el 78\% de varianza (Tabla 5). En el primer factor (56.3\% de varianza) se explica la relación inversa que existe entre las variables $\mathrm{SiO}_{2}, \mathrm{Al}_{2} \mathrm{O}_{3^{\prime}}$ $\mathrm{Fe}_{2} \mathrm{O}_{3}$ y TiO frente a $\mathrm{CaO}$ y $\mathrm{MgO}$; este factor es indicativo de la naturaleza calcítica de la arcilla utilizada en la realización de las ánforas y de la complementariedad entre los carbonatos $\mathrm{Ca}, \mathrm{Mg}$ y el resto de los minerales (filosilicatos, cuarzo y minerales pesados que incluyen óxidos de $\mathrm{Fe}-\mathrm{Ti}$ ).

El segundo factor que acumula el $22 \%$ de varianza, destaca la asociación $\mathrm{P}_{2} \mathrm{O}_{5}$ con $\mathrm{K}_{2} \mathrm{O}$ y su relación inversa con $\mathrm{Na}_{2} \mathrm{O}$, elementos asociados a las fracciones de filosilicatos y plagioclasas respectivamente; dicha variación inversa, podría interpretarse como debido a la utilización de técnicas de selección de arcillas, las cuales producirían cambios en la proporción relativa de filosilicatos (fracción fina) a expensas de la fracción menos fina de plagioclasas, por procesos de decantación, adición de desgrasante $\mathrm{u}$ otros.
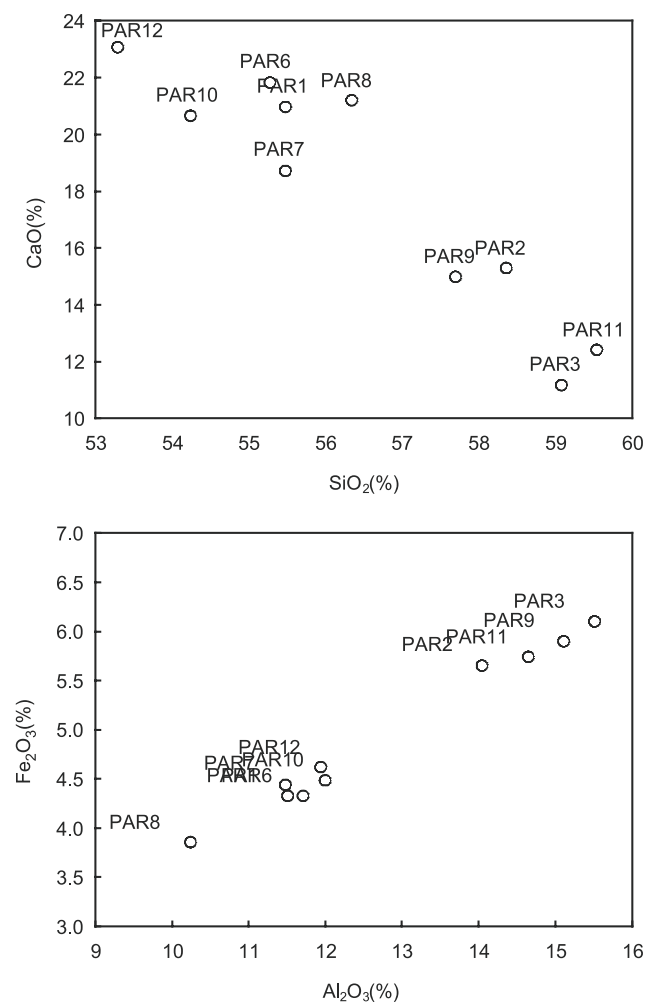

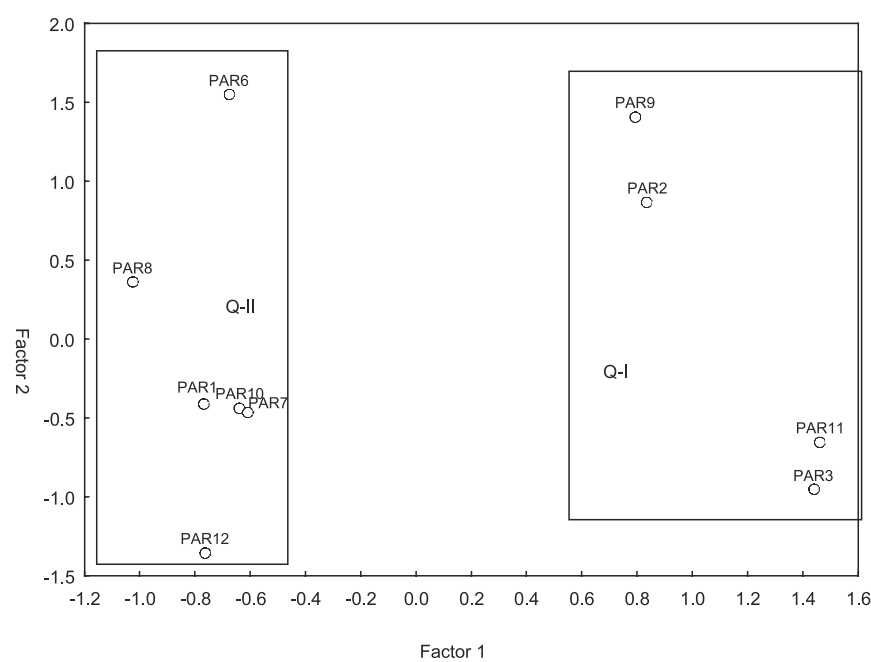

Figura 1 Diagrama Factor 1 vs Factor 2 con identificación de los grupos de ánforas Q-I y Q-II.

La representación de las marcas factoriales discrimina claramente los grupos de cerámicas Q-I y Q-II en base al factor 1 (Figura 1); las cerámicas del grupo Q-I presentan los siguientes límites de composición: $\mathrm{CaO}<18 \%, \mathrm{SiO}_{2}>57 \%, \mathrm{Al}_{2} \mathrm{O}_{3}>14 \%$, $\mathrm{Fe}_{2} \mathrm{O}_{3}>5 \%$, frente a las del grupo Q-II. De la interpretación de las tipologías que presentan las cerámicas pertenecientes al grupo QI se deduce que está integrado por ánforas de producción local, mientras que el grupo de ánforas Q-II integra las tipologías anfóricas más diversas, y probablemente se fabricaron en alfares diferentes a los locales. Los diagramas de correlación entre variables (Figura 2) indican la probable utilización de distintas técnicas de preparación de las pastas locales y foráneas; las cerámicas pertenecientes al grupo Q-II
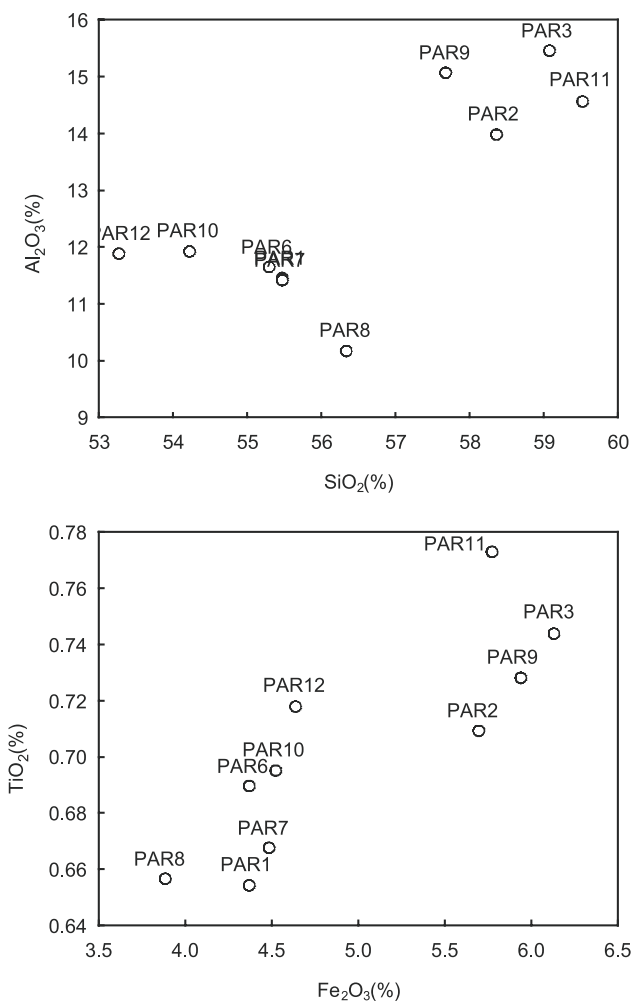

Figura 2 Diagramas de correlación e identificación de los grupos Q-I y Q-II. 
probablemente se elaboraron a partir de una arcilla depurada por un proceso de legivación y/o decantación; así se produce la eliminación de las fracciones más groseras, en este caso carbonatos, cuarzo y feldespatos, produciéndose un incremento sistemático en la fracción arcilla y por tanto de las variables $\mathrm{SiO}_{2}, \mathrm{Al}_{2} \mathrm{O}_{3}$, lo que se traduce en la variación inversa entre estas variables y $\mathrm{CaO}$ y $\mathrm{MgO}$ (Figura 2). Sin embargo en el grupo Q-I se observa el incremento sistemático de $\mathrm{SiO}_{2}$ y CaO ; la necesaria adición de ambos componentes en proporciones variables se justificaría por la incorporación de desgrasante de composición silícico-cálcica o por mezcla de dos arcillas, una con abundantes carbonatos $\mathrm{Ca}, \mathrm{Mg}$ y la otra silícea. En consecuencia entre ambos conjuntos de cerámicas se evidencia su probable distinto origen a través de los patrones de variación de su composición química (Figura 2).

\subsection{Análisis morfométrico.}

La impronta de los procesos de producción de las pastas cerámicas se puede manifiestar en sus texturas [18,19]; la necesidad de cuantificar distintos parámetros texturales, de forma y tamaño del desgrasante y de los poros, se justifica por ser imprescindible para realizar análisis estadísticos comparativos entre distintas cerámicas. Asimismo, el análisis de la distribución de la granulometría de los minerales que integran la pasta cerámica aporta una información que puede ser sustancial para la clasificación y el análisis de las técnicas utilizadas en su producción.
TABLA 5. VALORES DE VARIANZA CORRESPONDIENTES AL ANÁLISIS FACTORIAL.

\begin{tabular}{|l|c|c|}
\cline { 2 - 3 } \multicolumn{1}{c|}{} & Factor 1 & Factor 2 \\
\hline $\mathrm{SiO}_{2}$ & .892 & .169 \\
\hline $\mathrm{Al}_{2} \mathbf{O}_{3}$ & .959 & .034 \\
\hline $\mathrm{Fe}_{2} \mathbf{O}_{3}$ & .965 & .019 \\
\hline $\mathrm{MgO}$ & -.843 & .257 \\
\hline $\mathrm{CaO}$ & -.965 & .029 \\
\hline $\mathbf{N a}_{2} \mathbf{O}$ & -.023 & .661 \\
\hline $\mathrm{K}_{2} \mathbf{O}$ & -.134 & -.899 \\
\hline $\mathrm{TiO}_{2}$ & .850 & -.182 \\
\hline $\mathbf{P}_{2} \mathbf{O}_{5}$ & .187 & -.776 \\
\hline Var. Explicada & 5.07 & 1.98 \\
\hline \% Varianza & 56.3 & 22.0 \\
\hline
\end{tabular}

Para realizar el análisis granulométrico de cada lámina delgada, cada grano se ha asignado dentro de 15 clases de tamaños definidas por su diámetro; determinándose la superficie total de los granos de desgrasante. Con el objeto de comparar todas las láminas se han referido estos cálculos a una misma superficie unitaria, obteniéndose las curvas de distribución del desgrasante de cada lámina. Las gráficas de las granulometrías se han realizado representando las fracciones correspondientes a los distintos tamaños frente al área total de desgrasante (Figuras 3 y 4 ).
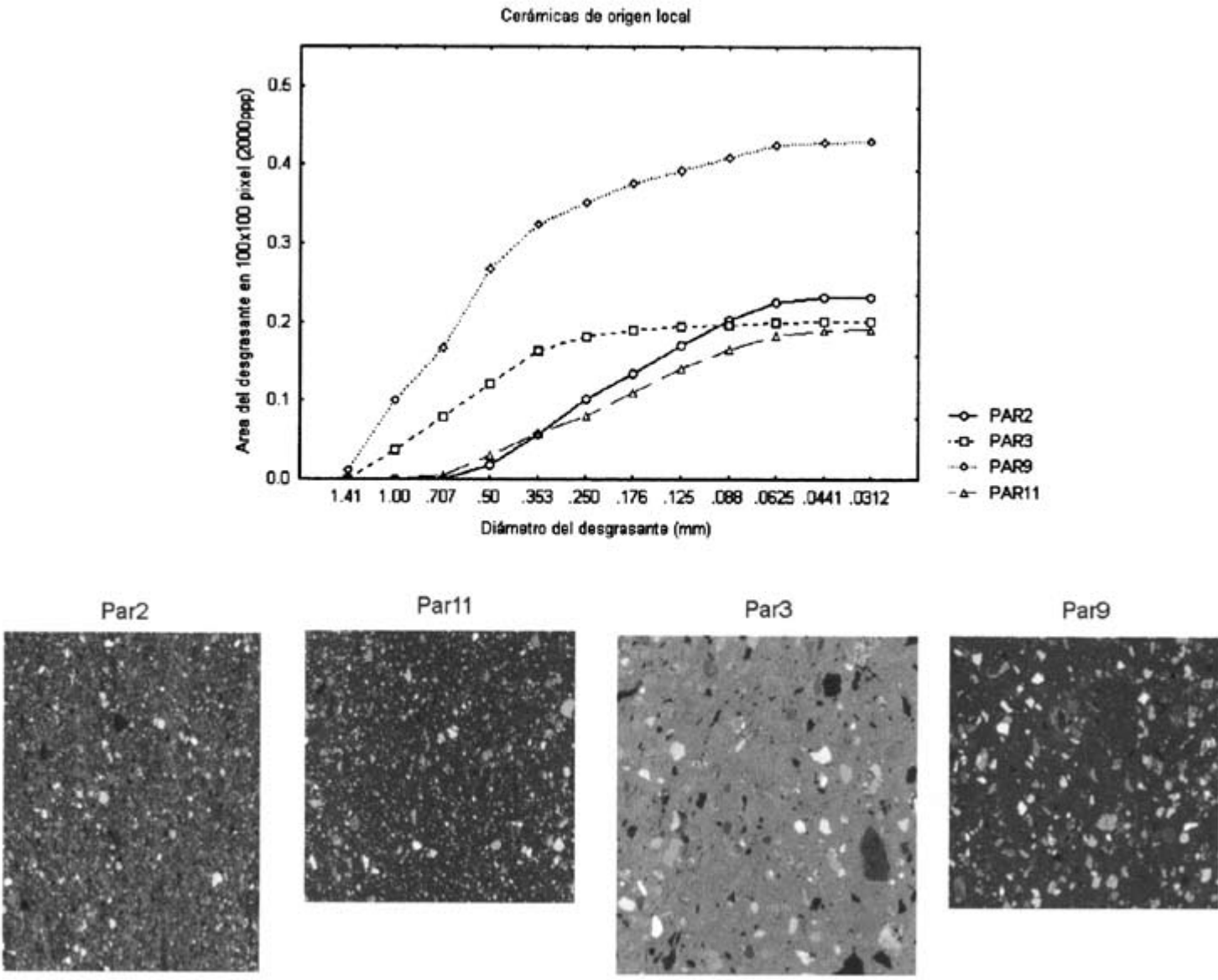

Figura 3 Granulometrías correspondientes a las cerámicas de origen local e imágenes de las láminas delgadas correspondientes (Grupo Q-I). 

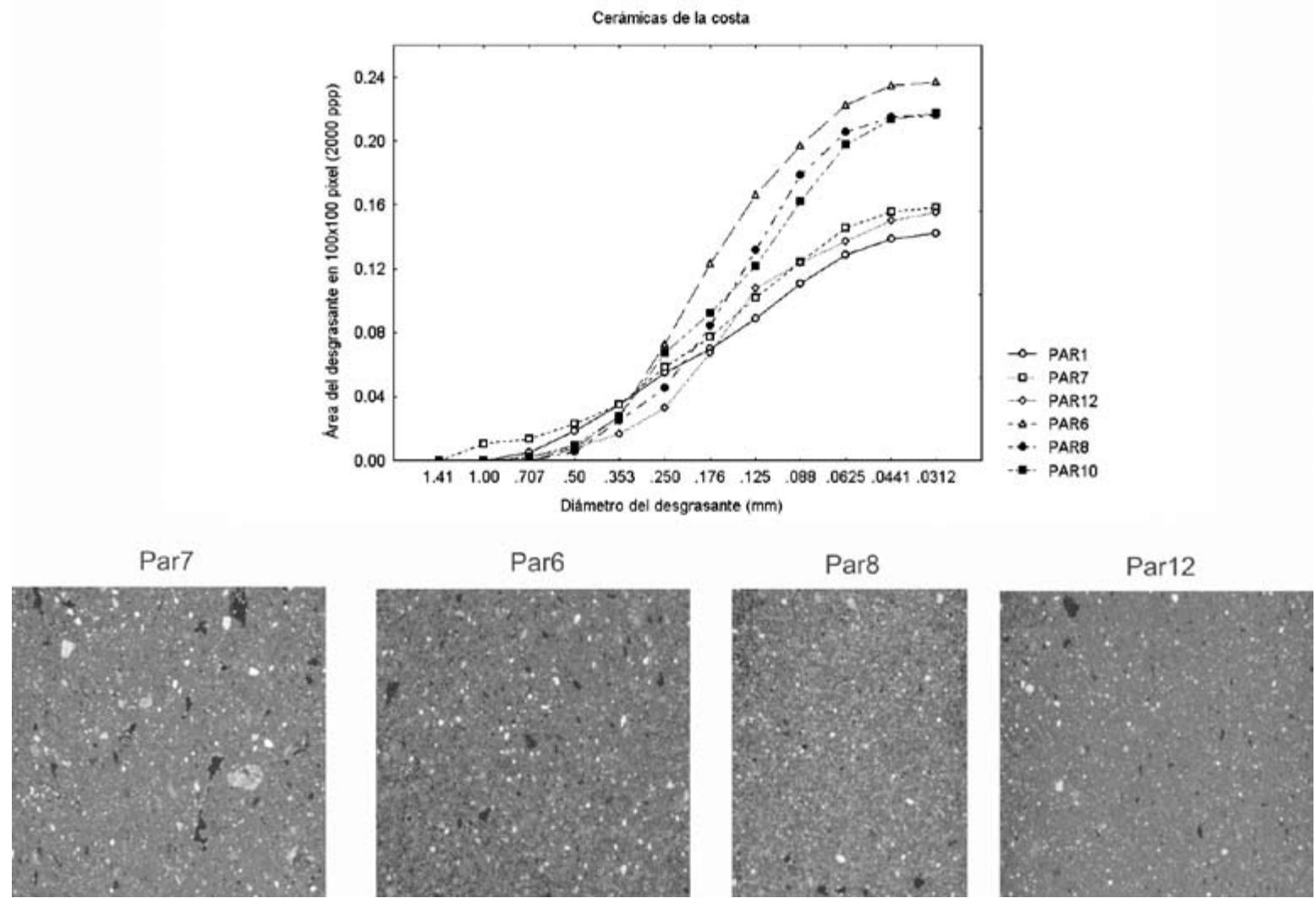

Figura 4 Granulometrías correspondientes a las cerámicas Q-II e imágenes de las láminas delgadas correspondientes.

Del análisis de las distribuciones granulométricas de las cerámicas Q-I, consideradas de origen local por los criterios mineralógicos y químicos anteriores (Figura 3), destaca la semejanza de las curvas granulométricas de las cerámicas Par2 y Par11 correspondientes a la tipología Dressel 20, la primera datada en el s.I d.C. y la segunda en el III d.C., lo que pone de manifiesto que la técnica de producción de este tipo de ánfora oleica se mantiene de forma tradicional a lo largo de tres siglos, utilizándose una arcilla de textura fina con un desgrasante de diámetro inferior a $0.5 \mathrm{~mm}$ (Figura 3). La cerámica Par3, de tipología Beltrán IIA, también elaborada en el mismo entorno, presenta una clara diferencia textural respecto de las anteriores, pues si bien la superficie total cubierta por el desgrasante en la cerámica es muy próxima, sin embargo sólo presenta granos de diámetro superior a $0.125 \mathrm{~mm}$ (Figura 3). Mayor diferencia se observa respecto de la granulometría de la cerámica Par9 en que se sugiere la presencia de dos poblaciones de granos minerales, definidas por un límite de $0.5 \mathrm{~mm}$ de diámetro, asociables a la mezcla de dos arcillas diferentes para la elaboración de las pastas; en esta cerámica se observa que la contribución del desgrasante a la superficie total de la lámina delgada es aproximadamente el doble de las otras cerámicas del grupo Q-I (Figura 3). Las muestras Par3 y Par9, cuya granulometría del desgrasante es de las menos finas, corresponden a ánforas para transporte de salazones.

La granulometría del conjunto de cerámicas que definen el conjunto Q-II presenta dos distribuciones que, aunque diferenciadas, son muy similares y corresponden a ánforas con texturas finas (Figura 4), cuyos tamaños de desgrasante son inferiores a $0.5 \mathrm{~mm}$ de diámetro. Se observa que las cerámicas Par1, Par7 y Par12 presentan un mismo tipo de distribución granulométrica; las ánforas Par6, Par8 y Par10 tienen una granulometría aún más fina que las anteriores, si bien con una superficie total de desgrasante mayor. Las arcillas utilizadas para elaborar todas estas cerámicas del grupo Q-II presentan no sólo una elevada homogeneidad mineralógica, sino también granulométrica (Figura 3), lo que reafirma la probable utilización de procedimientos de legivación y/o decantación de la arcilla original, tal como se ha apuntado anteriormente en la interpretación de su composición química. Las pequeñas diferencias que se observan entre las granulometrías de las distintas muestras de este grupo (Figura 3) pueden deberse a variaciones en los tiempos de sedimentación utilizados o eventualmente a que proceden de talleres distintos, que básicamente utilizan la misma arcilla y tecnología para su preparación; dichos procedimentos de elaboración se mantendrían entre los siglos I a III d.C como se desprende de la cronología de este grupo de ánforas (Tabla 1).

\section{CONCLUSIONES}

El análisis de la variabilidad composicional mineralógica y química de las arcillas estudiadas permite identificar un reducido grupo de tres muestras (Par5, Par13 y Par14) de probable importación, lusitana (Par 5) y campaniense de Italia (Par13). 
Además se han diferenciado por criterios mineralógicos, químicos y granulométricos dos conjuntos de ánforas, uno de producción local, y el otro aún no identificado, pero de probable localización en la costa, cuyas producciones abarcan el periodo de ocupación de los hornos excavados, es decir, entre los siglos I y III d.C. La mineralogía del desgrasante (minerales no plásticos) que incorporan las arcillas utilizadas en ambos centros de producción se caracterizan por su naturaleza calcárea.

Se ha determinado la intensidad relativa de los procesos de cocción entre las ánforas adscrita a los ss. I y III d.C., observándose que las temperaturas para elaborar las ánforas del s.III d.C. se sitúan en torno a $750^{\circ}-800^{\circ} \mathrm{C}$ frente a las más elevadas $900^{\circ}-950^{\circ}$ del s.I d.C., y se constata que en todos los casos la cocción ha tenido lugar en ambiente oxidante.

Las ánforas realizadas en los dos centros de producción diferenciados se discriminan tanto por las arcillas utilizadas, como por las técnicas empleadas en la preparación de las pastas. En la elaboración de las cerámicas locales se ha identificado la probable adición de desgrasante o mezcla de arcillas, mientras que en el otro centro productivo se ha aplicado la depuración de arcillas por procesos de legivación o decantación para la obtención de las pastas cerámicas; las cerámicas de textura más fina, así como de granulometría más constante, son las producidas por procesos de legivación, mientras que la variabilidad textural de las cerámicas de producción local es mayor.

El análisis morfométrico y granulométrico del desgrasante cerámico junto al análisis de la composición química de la pasta cerámica, ha permitido diferenciar dos probables orígenes distintos del conjunto de ánforas y sugiere la probable utilización de diferentes sistemas de preparación de las materias primas.

\section{BIBLIOGRAFÍA}

1. M.A. Tabales. "El Hospital de las Cinco Llagas de Sevilla. Investigaciones Arqueológicas en el Parlamento de Andalucía". Anuario Arqueológico de Andalucía 1998. Ed. Consejería de Cultura de la Junta de Andalucía. Sevilla 2001.
2. M.A. Tabales. "Excavación de los hornos romanos en el Hospital de las Cinco Llagas. Segunda fase". Anuario Arqueológico de Andalucía 1999. Ed. Consejería de Cultura de la Junta de Andalucía. Sevilla 2002.

3. M. Beltrán. "Guía de la cerámica romana". Libros Pórtico. Zaragoza, 1990.

4. M. Vegas. "Cerámica común romana del Mediterráneo occidental". Barcelona, Universidad de Barcelona, Instituto de Arqueología y Prehistoria. Publicaciones Eventuales n²2.1973.

5. M.A. Mezquíriz. "Tipología de la Terra Sigillata Hispánica". Bol. Museo Arqueológico Nacional. Monografías n¹, 2. Madrid, 1983.

6. J.W. Hayes. "Late roman pottery". British School at Rome. London, 1972.

7. G. W. Brindley, G. Brown. "Crystal structures of clay minerals and their X ray identification". London Min. Soc.. London, 1980.

8. A.J. Polvorinos, A. Gómez Morón. "Adaptación de un digitalizador de películas fotográficas para el análisis morfométrico de cerámicas arqueológicas", pp.153-159. Caesaraugusta vol. 73, II Congreso Nacional de Arqueometría, Zaragoza (España) 1997. Ed. Inst. Fernando El Católico, Zaragoza 1999.

9. A.G. Fabbri. "Image Processing of Geological Data". p.224, Van Nostrand Reinhold, New York (USA). 1998.

10. A.J. Polvorinos. "Contribución de la granulometría del desgrasante a la clasificación de texturas cerámicas arqueológicas", pp.341-348. III Congreso Nacional de Arqueometría, Sevilla (España) 1999. Editores: B.Gómez y col. Sevilla 2001.

11. R.C. González, R.E. Wods. "Digital Image Processing". Addison-Wesley Reading. Massachusets (USA), 1987.

12. J.C. Russ. "The Image Processing Handbook". CRC Press Inc. New York 1995.

13. J.C.Davis . "Statistics and data analisis in geology". John Willey, New York, 1986.

14. B. Velde y I.C. Druc. "Archaeological ceramic materials. Origin and utilization". Springer-Verlag, Berlín, 1999.

15. P.Mirti. "On the use of colour coordinates to evaluate firing temperatures of ancient pottery". Archaeometry 40,45-57 (1998).

16. J. Molera, T. Pradell , M. Vendrell-Saz "The colours of Ca-rich ceramic pastes: origin and characterization" Applied Clay Science 13, 187-202 (1998).

17. M.P. Riccardi, B. Messiga, P. Duminuco "An approach to the dynamics of clay firing" Applied Clay Science 15, 393-409 (1999).

18. Middleton,A.P. Freestone,I.C. and Leese, M.N. "Textural analysis of thin sections:evaluation of grain sampling procedures". Archaeometry 27, 164 74 (1985).

19. Mason, R.B. “Criteria for the petrographic characterization of stonepaste ceramics". Archaeometry 37,2 307-321 (1995).

Recibido: 11.10 .02

Aceptado: 24.02 .03 